Bangladesh J. Anat. 2011; 9(1) : 53-58

\title{
A Comparative Study of Effects of Different Grades of Maternal Established Diabetes Mellitus on Placental and Neonatal Weight
}

\author{
AHMM Mawla Chowdhury ${ }^{1}$, Khondker Manzare Shamim² ${ }^{2}$ Roxana Ferdousi ${ }^{3}$, \\ Jahan Ara Begum ${ }^{4}$, Laila Anjuman Banu ${ }^{5}$
}

\begin{abstract}
:
Context: Aiming the effects of severity of diabetes mellitus on human placenta and the neonatal outcome, a quantitative study at the macroscopic level was designed.
\end{abstract}

Material and Methods: Sixty post caesarean section human placentae were studied of which thirty were from mothers having established diabetes mellitus considered as EDM and thirty were from control mother having no diabetes mellitus. EDM mothers were treated with insulin. Venous plasma glucose level (fasting and 2 hours after breakfast) of the EDM mothers in $2^{\text {nd }}$ and $3^{\text {rd }}$ trimester were recorded and the mean of the values were calculated.

Results: The values ranged from 5.93 to $10.10 \mathrm{mmo} / \mathrm{L}$ and the mean was $7.28 \pm 0.99 \mathrm{~m} \mathrm{~mol} / \mathrm{L}$. The mothers having EDM were grouped according to the mean venous plasma glucose level. The mothers having a mean level up to $8.3 \mathrm{~m} \mathrm{~mol} / \mathrm{L}$ and those having a level above $8.3 \mathrm{~m} \mathrm{~mol} / \mathrm{L}$ were designated as the Low-EDM and HighEDM group respectively. Placental weight in Control, Low-EDM and High-EDM groups were 414.93 \pm 95.41 , 403.83 $\pm 68.53 \mathrm{gm}$ and $446.33 \pm 82.23 \mathrm{gm}$ respectively. The value showed lower mean value in Low-EDM group. The difference did not reach a significant level. The neonatal weight in Control, Low-EDM and High-EDM groups were 2958.33 $\pm 537 \mathrm{gm}, 2997.91 \pm 540 \mathrm{gm}$ and $3300.00 \pm 379 \mathrm{gm}$ respectively. The weight of the neonates did show a tendency towards being heavier in EDM groups but did not reach the significant level. There was a significant positive correlation between the neonatal weight and placental weight in control and Low-EDM group.

Key words: Established diabetes mellitus, Placenta, Neonates

Introduction:

The placenta brings the maternal and foetal circulation in close contact over a large area and involves in the transfer of maternal nutrients, oxygen and heat to the foetus and in reverse transfer of metabolic waste products to the maternal circulation. The architecture of the placenta has been claimed to be changed in maternal diseases like Diabetes Mellitus. 1,2,3,4 In normal placenta protein synthesis and degradation rates progressively declines over the last weeks of gestation. ${ }^{5}$ Because in the placenta of diabetic mothers, synthetic rate of protein remained

1. Associate Professor, Dept. of Anatomy, Sir Salimullah Medical College, Dhaka.

2. Professor \& Chairman, Dept. of Anatomy, BSMMU, Dhaka

3. Professor \& Head, Dept. of Anatomy, Anwar Khan Modern Medical College, Dhaka.

4. Professor \& Head, Dept. of Anatomy, Northern International Medical College, Dhaka

5 Professor, Dept. of Anatomy, BSMMU, Dhaka.

Correspondence: Dr. AHMM Mawla Chowdhury unchanged where as protein degradation stops, as a result more placental tissue, there by increase of placental weight. ${ }^{5}$ Degree of metabolic control of the maternal diabetes are important variables to be considered when studying the placenta. ${ }^{6}$

Ante partum maternal hyperglycaemia in diabetic pregnancy is associated with impaired uterine blood flow. ${ }^{7}$ Uteroplacental ischaemia could be responsible for most of the observed placental changes. A long term compensatory mechanism owing to secure a sufficient nutrient supply to the foetus to be active behind these changes to the foetus. ${ }^{8}$

Increasing number of diabetic patients appearing in obstetric clinics has stimulated a growing interest in the subject of diabetes in pregnancy. Studies on the placenta of Bangladeshi women, in this regard is scanty calling for increased attention towards it.

Materials and method:

Thirty placentae were collected from the mothers who were the patients registered by the Diabetic 
Association of Bangladesh as having established diabetes mellitus (EDM) before the onset of current pregnancy .All the mothers were treated with insulin during the period of gestation. The venous plasma glucose level (fasting and 2 hours after breakfast) in $2^{\text {nd }}$ and $3^{\text {rd }}$ trimester as available from the patients record book of the Diabetic Association of Bangladesh were recorded. The mean of these values were calculated for each patient. The mothers having established diabetes mellitus (EDM) were grouped i.e.graded according to the venous plasma glucose levels. The mothers with a mean level up to $8.3 \mathrm{~m} \mathrm{~mol} / \mathrm{L}$ were grouped as the "Low- EDM group" while those having a level above $8.3 \mathrm{~m} \mathrm{~mol} / \mathrm{L}$ were designated as the "High- EDM group. ${ }^{9} \mathrm{~A}$ Control group of placentae was obtained from thirty healthy women who were similar to the study group of diabetic women with respect to age, weight, height and parity. Undergoing caesarian section, all mothers gave birth to a living baby after completion of a gestational period between 37 weeks and 40 weeks in the Department of Obstetric \& Gynaecology of BIRDEM Hospital, Dhaka. The mother who had a previous history of hypertension, pre eclampsia or had an Rh negative blood group or was positive for VDRL \& HBSAg were excluded from the study.

Each of the placenta was collected just after delivery .The umbilical cord was cut off at $2.5 \mathrm{~cm}$ from its insertion. Each placenta was examined carefully. After removing blood and trimming the membranes the placenta was mopped with cotton wool. Then the weight of the placenta was recorded in grams (g). All the data of the mother and the weight of the neonate were collected from the mothers history sheet used in the Obstetric ward of BIRDEM Hospital, Dhaka.

\section{Results:}

In the present study, the findings of the three groups were compared with each other. Table-I shows the clinical data of the Control and EDM mothers. The mean fasting venous plasma glucose level during the $2^{\text {nd }}$ and $3^{\text {rd }}$ trimesters was significantly high in High- EDM group than of the Low- EDM group. The table also shows the mean of the duration of diabetes mellitus. Although the mean duration in the HighEDM group was higher than of the Low- EDM group, the difference did not reach a significant level (Table-I).

Table-I

Clinical data of the mother in different groups

\begin{tabular}{|c|c|c|c|c|}
\hline \multirow[t]{2}{*}{ Variable } & \multirow{2}{*}{$\begin{array}{l}\text { Control } \\
(n=30)\end{array}$} & \multicolumn{3}{|c|}{ Established diabetes mellitus(EDM) } \\
\hline & & $\begin{array}{l}\text { Low-EDM } \\
(\mathrm{LE})(\mathrm{n}=24)\end{array}$ & $\begin{array}{l}\text { High-EDM } \\
(\mathrm{HE})(\mathrm{n}=6)\end{array}$ & $\begin{array}{l}P \text { value for significant } \\
\text { difference between } \\
\text { groups }(P \leq 0.05)^{\star}\end{array}$ \\
\hline \multicolumn{5}{|c|}{ Fasting venous plasma glucose } \\
\hline level $(\mathrm{mmol} / \mathrm{L})=$ Mean $\pm \mathrm{SD}$ & $4.55 \pm 0.76$ & - & - & \\
\hline Range & $3.30-5.60$ & & & \\
\hline \multicolumn{5}{|l|}{ Venous Plasma glucose level } \\
\hline \multicolumn{2}{|c|}{ during $2^{\text {nd }}$ and $3^{\text {rd }}$ trimesters $(\mathrm{mmol} / \mathrm{L}) \neq$} & & & LE vs HE : 0 \\
\hline \multicolumn{2}{|l|}{ Mean \pm SD } & $6.89 \pm 0.63$ & $8.78 \pm 0.65$ & \\
\hline \multicolumn{2}{|l|}{ Range } & $5.93-8.15$ & $8.43-10.11$ & \\
\hline \multicolumn{5}{|l|}{ Duration of diabetes (years) } \\
\hline \multicolumn{2}{|l|}{ Mean \pm SD } & $2.81 \pm 1.57$ & $3.91 \pm 1.80$ & \\
\hline \multicolumn{2}{|l|}{ Range } & $1-6$ & $1.50-6.00$ & \\
\hline
\end{tabular}

Statistical significance level was set at $5 \%(P \leq 0.05)$. 
Fig-1 shows the frequency distributions of the mean venous plasma glucose level of the EDM groups during $2^{\text {nd }}$ and $3^{\text {rd }}$ trimesters. The figure reveals the glycaemic status of the group members.

Table-II: displays the neonatal weight, placental weight and neonatal weight- placental weight ratio in different groups. The mean values of the neonatal weight, placental weight and neonatal weight-placental weight ratio were highest in the High-EDM group. However the groups did not vary significantly from each other in this regard.

Table-II

Neonatal weight and placental weight ratio in different groups

\begin{tabular}{lccc}
\hline Variable & $\begin{array}{c}\text { Control } \\
(\mathrm{n}=30)\end{array}$ & \multicolumn{2}{c}{ Established diabetes mellitus(EDM) } \\
& & & \\
& & & \\
Placental weight $(\mathrm{g})$ & $414.93 \pm 95.41$ & $403.83 \pm 68.53$ & $446.33 \pm 82.23$ \\
Mean \pm SD & $220-680$ & $239-520$ & $348-540$ \\
Range & & & \\
Neonatal weight (g) & $2958.33 \pm 537.56$ & $2997.91 \pm 540.62$ & $3300.00 \pm 379.4)$ \\
Mean \pm SD & $1500-4100$ & $2000-4000$ & $2800-3700$ \\
Range & & & \\
Neonatal weight -placental weight ratio & & $7.47 \pm 0.84$ & $7.55 \pm 1.05$ \\
Mean \pm SD & $7.25 \pm 1.08$ & $6.02-9.69$ & $5.74-8.52$ \\
Range & $5.41-8.93$ & & \\
\hline
\end{tabular}

Statistical significance level was set at $5 \%(P \leq 0.05)$.

Analysis of variance (ANOVA) was performed to make a comparison among Low-EDM, High-EDM and Control groups. No significant difference was found for any of the variables.

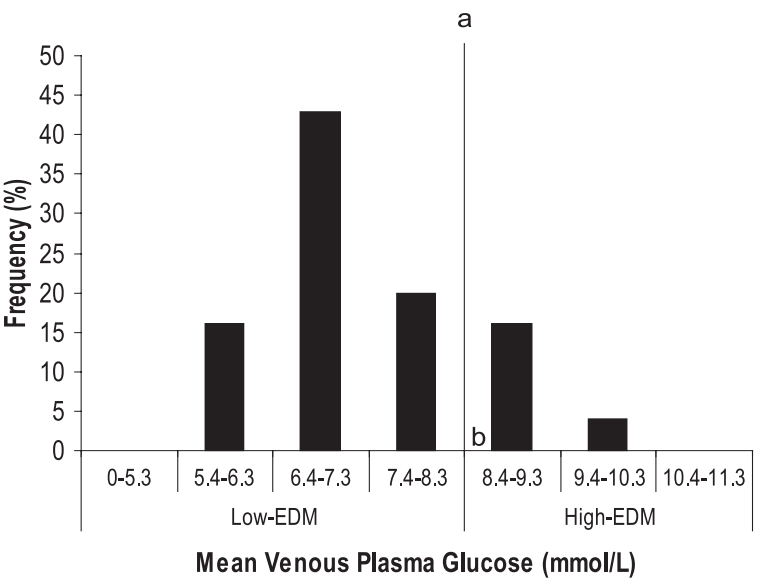

Fig. 1 shows the frequency distributions of the mean venous plasma glucose level of the EDM groups during $2^{\text {nd }}$ and $3^{\text {rd }}$ trimesters.

The vertical line ab represents the cut-off value of mean venous plasma glucose between the LowEDM and High-EDM groups.
Discussion:

Reports on the weight of the placenta are variable. ${ }^{4,10,12,13}$ Several workers have reported increased placental weight in diabetic pregnancy in humans. ${ }^{10-13}$ On the other hand in well controlled diabetics, some authors have even found no difference in placental weight as compared to control group. Pedersen ${ }^{14}$ have even found smaller placenta in diabetic mothers with intrauterine growth retardation in diabetes.

Honda $^{2}$ and Mayhew ${ }^{15}$ observed no significant difference of the placental weight in established diabetic and control group under tight metabolic control of hyperglycaemia keeping the mean blood glucose level $6.6 \mathrm{mmol} / \mathrm{L}$ and $6.0 \mathrm{mmol} / \mathrm{L}$ respectively. Teasdale ${ }^{16}$ worked on placentae of white class B diabetic where classification takes duration in addition to severity into consideration. 
In the present study, the neonatal (birth ) weight did not show any significant difference in the EDM groups as compared to the control group. The mean value was higher in the diabetic groups. The mean neonatal weight in the High EDM-group was also not very different from that in the LowEDM group and control group because compensatory mechanism are believed to bring about parenchymal changes (including hypoplasia), that have been related by various authors to increased placental weight. Anwar ${ }^{13}$ noticed a similar trend in overt (established) diabetes mellitus and Barua ${ }^{17}$ found significantly greater neonatal weight in gestational diabetes where as Rahman ${ }^{18}$ found in gestational diabetes a similar tendency that did not reach a significant level.

The question of quantitating the effect of severity of established diabetes mellitus on the changes that might occur in the placenta in the disease as well as on the fetus is not very easy to resolve. While researchers have varied in their findings and postulations, the present study did not come up with a single statistically significant difference between the less severe Low-EDM group and the more severe High- EDM group. The HighEDM group also had a tendency towards having a heavier placenta than the less severe Low-EDM group. This was expected, as Clarson ${ }^{19}$ et al. (1989) observed a significant correlation between placental weight and neonatal weight in 30 cases- including overt diabetes of White ${ }^{20}$ classes B.C,D and R and gestational diabetes cases (including some cases of premature delivery). However, the possible tendency of having a heavier baby was not proportionate to these findings. The positive correlation of placental weight with neonatal weight did not reach a significant level in the High-EDM group (while these correlations were significant in case of the other two groups). This particular aspect of the results might just be a coincidence, or might be an indication of the limit to which the placenta could change itself in the line of providing adequate oxygen and nutrition to an enlarged fetus. Nevertheless, Desoye and Shafrir (1996) ${ }^{21}$ suggested that fetal hypertrophy in diabetes should be explained on a metabolic basis rather than by increased placental transfer of nutrients as, in their opinion, there is no direct relationship between uteroplacental blood flow and fetal birth weight in diabetes. Knight et al. (1983, cited by Laurini et al. 1987) ${ }^{11}$ also suggested that wellcontrolled diabetic pregnancy does not prevent macrosomia.

Mayhew and Sisley $(1998)^{22}$ identified some probable causes of inconsistencies in placental findings in diabetes mellitus by various authors. They stated that "at least part of the inconsistency might be due to arbitrary tissue sampling, modelbased morphometry, and a failure to cater for various confounders including mode of delivery, gender of neonate, duration and severity of diabetes mellitus, mixing of patients differing in duration and severity and quality of glycaemic control. The present study could not remain out of most of these problems. In addition, the High -EDM group was very small $(n=6)$. Researchers have also varied in their methods when they have addressed the question of severity of diabetes. The well documented White 22 classification has been used by several workers, but often several classes have been included in a single study reducing the sample size for a particular class. This classification takes duration, in addition to severity, into consideration. The present study could not label individual cases by these classes, but most of the cases ( 25 out of 30 cases) most likely belonged to White ${ }^{20}$ Class B. As mentioned in Materials and Methods, the Low-EDM and High-EDM groups of the present study were defined on the basis of the mean of the fasting and 2-hours-after-breakfast venous plasma glucose levels in the second and third trimesters of pregnancy. Those mothers having a mean value up to $8.3 \mathrm{mmol} / \mathrm{L}$ were taken into the Low-EDM group while those having a value more than 8.3 $\mathrm{mmol} / \mathrm{L}$ were considered to form the High-EDM 
group. Thus, quite a few of the values remained close to the cut-off value of $8.3 \mathrm{mmol} / \mathrm{L}$. In addition, only $12.5 \%$ of the Low-EDM group values were within $6 \mathrm{mmol} / \mathrm{L}$, the value considered for defining "well-controlled" diabetes by Mayhew and Sisley ${ }^{22}$, who pointed out that apart from a few minute changes normal placental features are preserved in well-controlled diabetes regardless of diabetic classes, the expected differences between the Low- and High-EDM groups of the present study might have been minimized.

\section{References:}

1. Bjork O, Persson B. Placental changes in relation to the degree of metabolic control in diabetes mellitus. Placenta 1982; 3:367-78.

2. Honda M, Toyoda C, Nakabayashi M, Omori Y. Quantitative investigations of placental terminal villi in maternal diabetes mellitus by scanning and transmission electron microscopy. Tohoku J Exp Med 1992; 167:24757.

3. Mayhew TM. Patterns of villous and intervillous space growth in human placentas from normal and abnormal pregnancies. Eur J Obstet Gynecol Reprod Biol 1996:68:75-82.

4. Winick M, Noble A. Cellular growth in human placenta. II. Diabetes mellitus. J Paediatr 1967; 71:21 6-9.

5. Robinsson J, Canavan JP, Alicial J, Haj E, Goldspink DF. Maternal diabetes in rats. I. Effects of placental growth and protein turnover. Diabetes 1988; 37:1665-70.

6. Bjork O, Persson B. Villous structure in different parts of the cotyledon in placentas of insulin-dependent diabetic women. Acta Obstet Gynecol Scand 1984; 63:37-43.

7. Widness JA, Teramo KA, Clemons GK, Voutilainen $\mathrm{P}$, Stenman UH, Mckinlay SM, et al. Direct relationship of antepartum, glucose control and fetal in erythropoietin human type I (insulin-dependent) diabetic pregnancy. Diabetologia 1990; 33:378-83
8. Eriksson UJ, Jansson L. Diabetes in pregnancy: decreased placental blood flow and disturbed fetal development in the rat. Paediatric Research 1984; 18:735-8.

9. Karlsson K, Kjellmer I. The outcome of diabetic pregnancies in relation to the mothers' blood sugar level. Am J Obstet Gynecol 1972; 112(2): 213-20.

10. Teasdale F. Histomorphometry of placenta of the diabetic women: class A diabetes mellitus. Placenta 1981; 2:241-52.

11. Laurini RN, Visser GHA, Ballegooie EV, Schoots CJF. Morphological findings in placentas of insulin-dependent diabetic patients treated with continuous subcutaneous insulin infusion (CSII). Placenta 1987; 8:15365.

12. Mayhew TM, Sorensen FB, Klebe JG, Jackson MR. The effect of mode of delivery and sex of newborn on placental morphology in control and diabetic pregnancies. J Anat 1993b; 183:545-52.

13. Anwar $\mathrm{S}$. The gross and histomorphological features of the human diabetic placenta a case control study [thesis]. Dhaka: University of Dhaka, 1999.

14. Pedersen JF, Molstead-Pedersen L. Early growth retardation in diabetic pregnancy. $\mathrm{Br}$ Med J 1979; 1:18-9.

15. May hew TM, Sorensen FB, Klebe JG Jackson MR, Growth and Maturation of Villi in placentas from well controlled diabetic women. Placenta 1994; 15:51-65.

16. Teasdate F. Histomorphometry of human placenta in class $B$ diabetes mellitus Placenta 1983; 4:1-12.

17. Barua R. Macroscopic and Microscopic changes of human placenta in gestational diabetes and eclampsia [thesis], Dhaka: BSMMU, 2002. 
18. Rahman A. Gross Morphological feature of human placental in Gestational Diabetes mellitus and eclampsia [thesis], Dhaka: BSMMU, 2002.

19. Clarson C, Tevaarwerk GJM, Harding PGR, Chance GW, Host MD. Placental weight in diabetic pregnancies. Placenta. 1989; 10: 27581.
20. White P. Classification obstetric diabetes. Am J Obstet Gynecol 1978;130:228-30.

21. Desoye G, Shafrir $\mathrm{E}$. The human placenta in diabetic pregnancy. Diabet Rev 1999; 4:70-89.

22. Mayhew TM, Sisley I. Quantitative studies on the villi, trpjahoblast and intervillous pores of placentas from women with well-controlled diabetes mellitus. Placenta 1998; 19:371-7. 